\title{
El colectivo como vía de acceso al trabajo: el caso de los trabajadores vitícolas de Mendoza, Argentina (1995-2010)
}

Lorena Poblete Doutora en Sociología (École des Hautes Études en Sciences Sociales de París, Francia) Investigadora del Instituto de Desarrollo Económico y Social Investigadora asociada al Institut Marcel Mauss Profesora de la Universidad Nacional de San Martín lorena.poblete@conicet.gov.ar

\begin{abstract}
Resumen La organización del trabajo en la viña que caracterizó al modelo de producción centrado en el mercado interno tenía como eje la familia. Gracias a que los distintos miembros de la familia participaban del trabajo agrícola, este tipo de organización podía adaptarse a las demandas del ciclo de labranza.

A partir de los años 1990, cuando el modelo de producción vitivinícola se orienta hacia al mercado externo, se introducen nuevas tecnologías agrícolas, y por consiguiente se modifica el modo en que se organiza el trabajo.

En este contexto de transformación del mercado de trabajo surgen dos formas asociativas que permiten la inserción laboral de los trabajadores expulsados por el nuevo modelo. El objetivo de este estudio es analizar la manera en la que se constituyen y funcionan estos colectivos. Los casos estudiados son: el uso colectivo de la categoría trabajador autónomo y las cooperativas de trabajo informales.
\end{abstract}

Palabras clave: colectivo; trabajo agrícola; reconversión industrial; inseguridad laboral; Argentina.

$\mathrm{E}$ L TRABAJO EN LAS REgIONES Vitícolas consta de dos tipos de actividades: actividades permanentes y actividades estacionales. Dentro de estas últimas, la importancia de la cosecha significó siempre un desafío en términos de gestión del trabajo.

El modelo de organización del trabajo que caracterizó a la producción vitivinícola desde principios del siglo XX hasta fines de los años 1980, tenía como núcleo central a la familia. La familia en tanto que unidad de producción dio lugar a un modo de gestión de la mano de obra bastante elástico, ya que un número variables de trabajadores familiares no remunerados podía incorporarse al trabajo agrícola para satisfacer las demandas del ciclo cultural. Durante la cosecha, dado que los trabajadores locales no eran suficientes, se incorporaban numerosos trabajadores temporarios que venían de otras regiones agrícolas, o incluso de áreas urbanas.

A partir de los años 1990, se produce una importante recomposición del sector vitivinícola de Mendoza que se traduce en nuevas formas de organización del trabajo agrícola. La reestructuración de la producción vi-

1 La última etapa de esta investigación se desarrolló en el marco del programa Naturalización y Legitimación de las Desigualdades Sociales en la Argentina Reciente, dirigido por el Dr. Alejandro Grimson, en el IDAES, Universidad Nacional de San Martín (UNSAM). 
tivinícola se debe a un cambio en los objetivos de comercialización, por un lado, y por otro, a la incorporación de nuevas tecnologías que acompañan esa reorientación. La vitivinicultura mendocina, que estuvo centrada en la producción de vinos comunes para el mercado local, a principios de los 1990, comienza a producir vinos de alta gama para la exportación. Esta reorientación comercial necesita una incorporación de tecnologías agrícolas que permitan obtener productos capaces de responder a las exigencias del mercado internacional. Las nuevas tecnologías produjeron un reordenamiento de los puestos de trabajo, así como la redefinición de la manera en que el mismo se realiza dentro de las bodegas y propiedades vitícolas.

En lo que se refiere al trabajo agrícola, el nuevo modelo de producción vitivinícola demanda más trabajadores calificados que el modelo anterior, pero también menos trabajadores no calificados permanentes. El trabajo se organiza entonces en torno a un pequeño grupo de trabajadores muy calificados que desarrollan actividades permanentes y un gran número de trabajadores no calificados que realizan tareas estacionales.

Para lograr mayor competitividad en el mercado internacional, las empresas vitivinícolas instauran nuevos modos de gestión flexible del trabajo que pasan, en la mayoría de los casos, por la externalización de la mano de obra. Las formas clásicas de subcontratación son dos: la contratación de empresas prestadoras de servicios y la contratación de mano de obra a través de agencias de empleo eventual (Servais, 2010, Morin, 1999). Sin embargo, estas no son las formas más utilizadas en las zonas vitivinícolas de Mendoza. Otras formas ad hoc de externalización de la mano de obra, que se desarrollan en los límites de la legalidad, cobran importancia en los últimos 15 años. Por una parte, se observa la utilización de la categoría trabajador autónomo de manera extensiva, sobre todo desde que se crea en 1998 la categoría autónomo monotributista $^{2}$ rural. Por otra parte, aumenta enormemente la presencia de cooperativas de trabajo en las regiones rurales de Mendoza.

El objetivo de este artículo es analizar la manera en la que estas formas ad hoc de externalización de la mano de obra se transforman en modos alternativos de gestión del trabajo, o mejor dicho, en modos alternativos de autogestión de la inserción al mercado de trabajo.

Se trata de un estudio cualitativo, basado principalmente en los datos obtenidos a lo largo de los trabajos de campo realizados en una región rural de Mendoza durante las cosechas de 1995, 1997, 1999 y
2010. En los distintos períodos, entrevistamos a numerosos trabajadores rurales. En total, contamos con 61 entrevistas en profundidad. En varias ocasiones entrevistamos a las mismas personas en distintos años. Esto nos permitió reconstruir trayectorias familiares que se inscriben en un proceso importante de transformación de la agroindustria vitivinícola, y que por ello dan cuenta de la complejidad de ese proceso.

El artículo se divide en tres partes, si bien es la tercera parte la que concentra el análisis de estos dos casos de autogestión de la integración al mercado de trabajo. En la primera parte, analizamos la estructura del modelo de organización del trabajo propio del tipo de producción vitivinícola que se desarrolló durante el siglo XX como antecedente indispensable para entender los cambios que sufre la vitivinicultura mendocina. En la segunda parte, presentamos el proceso de reconversión industrial que tiene lugar a partir de los años 1990. En la tercera parte, analizamos de qué manera se produce la reorganización del trabajo en las zonas rurales de Mendoza durante el proceso de recomposición del sector vitivinícola, haciendo hincapié en la constitución de colectivos invisibles gracias al uso extensivo y fraudulento de la categoría "trabajador autónomo", por una parte, y por otra, en la conformación de cooperativas ilegales de trabajo. El artículo termina con algunas reflexiones en torno al colectivo como medio de integración en mercados de trabajo hiperflexibilizados y fuertemente desestructurados como el mercado de trabajo rural de Mendoza.

\section{La familia: eje de la gestión del trabajo}

Antes de que se produjera la reconversión de la agroindustria vitivinícola en los años 90, la cultura de la viña estaba organizada en torno a la figura del contratista. El contratista es un actor que aparece con el desarrollo de la vitivinicultura alrededor de 1880, y que va adquiriendo con el correr de las décadas un lugar preponderante.

La ley lo define como "la persona que, en forma individual o con su núcleo familiar, trabaja personalmente en el cuidado y cultivo de la viña, percibiendo como contraprestación una retribución". La remuneración del contratista está compuesta por un sueldo mensual y por un porcentaje de la cosecha. El salario, pagado durante los diez meses del año agrícola (de 
mayo a febrero) en función de las hectáreas trabajadas, es fijado por paritarias, e incluye el aguinaldo. Según la ley, el porcentaje de los beneficios de la cosecha que corresponde al contratista resulta de una negociación entre el contratista y el patrón, sin embargo no puede ser inferior al $18 \%$.

El contratista goza de los derechos establecidos por las leyes laborales, previsionales y de accidentes de trabajo. Por consiguiente, está sujeto a la ley de despidos, y percibe asignaciones familiares. Tiene un contrato por tiempo determinado cuya duración es de un año agrícola, y se renueva automáticamente, a menos que alguna de las partes decida rescindirlo.

Son obligaciones del empleador el "proporcionar vivienda adecuada a las necesidades del contratista y su familia", suministrar los insumos necesarios para realizar el trabajo agrícola -maquinarias, productos químicos, animales, etc.-. El contratista, por su parte, tiene la obligación de realizar todas y cada una de las tareas descritas de manera detallada en la ley, ya que su incumplimiento es causal de ruptura del contrato de trabajo. Puede realizar dichas tareas con su grupo familiar o subcontratar personal.

La gestión del trabajo agrícola bajo estas condiciones no es sencilla, exige de los actores una gran flexibilidad dentro de una rigurosa organización de las tareas programadas en los distintos momentos del ciclo cultural. Estela y Jorge nos contaban, en 1997, de qué manera se organiza el trabajo agrícola a lo largo del año cuando se tiene un contrato como contratista:

Estela -Lo que pasa es que acá, pasando la cosecha, hay que esperar de ser mensual o quincenal. No es como digamos, semanal. Porque si usted cosecha de lunes a viernes, es sabido que el viernes en la tarde, terminando de cosechar le pagan las fichas, entonces uno puede comprarles las zapatillas a las criaturas al otro día. Pero ya terminando esta temporada, ahora hay que esperar que empiecen a trabajar, y o esperar la quincena los que son quincenales, y si no la mensualidad. Yo gracias a Dios no tengo niños chicos. Mi marido es mensual. Y hay que esperar todo el mes. Muchos pensarán que el contratista de la viña es el que gana más. No, gana menos. A cualquiera yo le daría el sueldo de mi marido, a ver si pasa el mes con eso. Que no lo va a pasar... ¡No lo va a pasar! No va a llegar ni siquiera a recibirlo y va a decir: ¿y con esto voy a pasar el mes? $\mathrm{Y}$ sin embargo nosotros nos las tenemos que arreglar, que es la mensualidad de ellos. Tenemos ayuda de mi hijo mayor, porque ha empezado a trabajar quincenal. Porque si no...y las chicas que por ahí trabajan. Pero sí, hay muchos que pensarán que es un sueldazo lo que ganan acá, pero no. No se gana muy bien.

Jorge -la única ganancia, como dice ella es el porcentaje de fin de año...

Estela -...de la cosecha...

Jorge - es lo único...
Estela -y acá empezando marzo el contratista no tiene sueldo hasta junio... Son tres meses. Tiene marzo, abril, mayo, a junio recién viene a cobrar. Y nosotros así, haciendo una cosecha por acá, una cosecha por allá, un trabajito por acá, y un trabajito por allá. Y así vamos juntando para ir teniendo para pasar esos tres meses.

Jorge -Como ser allá hemos terminado de cosechar en los de Delirio, y por eso estamos acá en la casa ahora...y si uno no hace así tampoco...Parado tampoco puede estar mucho tiempo.

Estela - No, sí, dos días, tres, es lo mucho que estamos en la casa nosotros parados. Y tenemos que salir. Y ahora en la temporada que él trabaja en el contrato, nosotros ya vamos atando. Pedimos atar, cosa de ir ayudando. Pero mientras tanto, hay que saber ir llevando la casa con la poca plata que pagan en la mensualidad.

El estatuto de contratista, al enmarcar al trabajo familiar no remunerado dentro de un contrato individual, incorpora la variabilidad de mano de obra demandada por la actividad vitícola a lo largo del año. Tres actividades concentran la mayor demanda de mano de obra: la poda, el atado y la cosecha. Las dos primeras se realizan mayormente incorporando a los distintos miembros de la familia. La última, dado que tiene que realizarse en un período de tiempo preciso respectando el nivel de madurez de los racimos solicitado, supone además la contratación de cosechadores externos.

Los cosechadores externos son, en muchos casos, trabajadores "golondrinas" que viajan por todo el país siguiendo las cosechas de distintos cultivos. Sin embargo, una parte de quienes realizan la cosecha está compuesta por los contratistas y sus familiares que, como nos contaban Estela y Jorge, van de finca en finca cosechando. Una vez que cumplieron con las tareas correspondientes a la propiedad que tienen a su cargo, los contratistas y sus familias trabajan como obreros temporarios en otras propiedades con el objetivo de generar ingresos durante el período en el que no cobran la mensualidad. Generalmente, en estas ocasiones trabajan como trabajadores no declarados.

El hecho de que la familia funcionara como eje de la organización del trabajo en las zonas vitícolas de Mendoza, permitió la movilización de trabajadores secundarios durante los momentos de mayor actividad laboral. Para las familias de contratistas, la cosecha representaba la ocasión de que los trabajadores inactivos o parcialmente activos participaran temporalmente en el mercado de trabajo. Por consiguiente, el número de trabajadores externos a la zona que trabajaba en la cosecha dependía de la capacidad de movilización de trabajadores inactivos instalados en la zona. Una mayor capacidad de movilización implicaba entonces la reducción de los costos de la cosecha, ya sea en términos de traslados, ya sea en términos de mediaciones. 
Este tipo de organización del trabajo, que tenía era funcional al modelo de producción vitivinícola destinado al mercado interno, no pudo adaptarse al nuevo modelo de producción. Las exigencias de calidad del mercado externo, que se traducen en la incorporación de nuevas tecnologías, demandan necesariamente otras formas de organización del trabajo aún más flexibles.

\section{La reconversión de la agroindustria vitivinícola}

A partir de mediados de los 1990, la agroindustria vitivinícola experimenta un amplio proceso de transformación. Este proceso aparece como consecuencia, por una parte, del agotamiento del modelo de producción vitivinícola existente, y por otra, de la promoción de un nuevo modelo agroindustrial estructurado en función de la exportación de vinos finos.

El modelo previo a la reestructuración, que tiene como objetivo principal satisfacer al mercado interno a través de la fabricación de vinos comunes, entra en crisis a raíz de dos factores principales: un cambio en la pauta de consumo de vino y problemas en la gestión familiar-empresarial de los establecimientos vitivinícolas. Por una parte, se observa una constante disminución del consumo de vino de mesa, ya que es reemplazado por otro tipo de bebidas. En 1970, el consumo era de 92 litros por persona; en 1980 de 76,3; en 1990 de 54,2; y en 1994 de 43,2 litros 3 (Gago y de la Torre, 1996). Por otra parte, la mayoría de las bodegas, constituidas como empresas familiares a finales del siglo XIX y principios del siglo XX, manifiestan importantes problemas de gestión al llegar a la tercera generación. Estos problemas se suman a la reducida capacidad de inversión que tienen estas empresas debido al endeudamiento adquirido durante los años 80 (Mellado, 2008, p. 355).

El nuevo modelo de producción, posibilitado por la apertura del mercado y la desregulación de la economía, se plantea como objetivo principal la producción de vinos de mayor calidad destinados a un mercado externo que había crecido un 50\% entre 1988 y 1998 (Neiman; Bocco, 2005, p. 206). Este modelo presupone una gran inversión en términos de tecnologías agrícolas e industriales para poder desarrollar actividades productivas de alto nivel; así como también, el desarrollo de circuitos de comercialización internacional. Estos dos requisitos resultan imposibles de alcanzar para la mayoría de las empresas vitivinícolas nacionales que se encuentran con problemas de gestión y que no pueden obtener créditos que les permitan encarar ese proceso de reconversión agroindustrial (Collado y Rofman, 2005). Por lo tanto, los actores con mayor capacidad para participar de ese proceso son las empresas extrajeras. Se calcula que entre 1990 y 1999 se invirtieron 523,3 millones de dólares (Aspiazu; Basualdo, 2001, p. 126) y entre 2000 y 2005, otros 123,4 millones (INV, 2000, 2005).

Según el relevamiento realizado por Aspiazu y Basualdo (2003) ${ }^{4}$, entre 1992 y 2002, 15 bodegas fueron compradas en su totalidad por capitales extranjeros, 4 por capitales locales y 2 por capitales mixtos. Durante esa misma época, 9 bodegas incorporaron capital proveniente de empresas extranjeras, 7 de grupos nacionales y 2 de sociedades mixtas. Además, desde 1992 hasta la fecha, se han creado alrededor 80 nuevos emprendimientos que cuentan, en la mayoría de los casos, con capitales extranjeros.

La recomposición del sector vitivinícola se observa también en el aumento de las hectáreas cultivadas y del tipo de variedades implantadas. Gracias a las nuevas tecnologías de riego, se incorpora una gran cantidad de hectáreas a la producción vitícola. Luego de la pérdida de más del $30 \%$ de la superficie cultivada que se produce durante los años 80 , en los 90 la superficie permanece estable, observándose un crecimiento de casi un $10 \%$ entre 2002 y 2008 (INV, 1978-2008). Las nuevas plantaciones corresponden exclusivamente a las cepas más demandadas por el mercado internacional: Cabernet Sauvignon, Pinot Noir, Merlot, Chardonnay, Sauvignon Blanc y Malbec. Las hectáreas implantadas con este tipo de variedades aumentan en un 67,5\% entre 1991 y 2001 (INV, 1978-2008).

Este proceso de transformación de la agroindustria vitivinícola no afecta de manera homogénea al sector vitivinícola en su conjunto. Sino que estructura un modelo dual de producción (Bocco et al., 2005) caracterizado por la superposición de dos marcos tecnológicos diferentes (Maclaine Pont; Thomas, 2009). Aún si la producción de vinos finos para la exportación aparece como el subsector más dinámico dentro de la vitivinicultura mendocina, la elaboración de vinos comunes destinada al mercado interno representa más de la mitad de la producción regional. Incluso, dentro de este subsector, muchas empresas

3 La disminución del consumo, que aparece como un elemento clave que justifica y, al mismo tiempo, promueve la reconversión del sector, no se revierte luego de la misma. En 2001, el consumo por persona/ por año es de sólo 26 litros, y en 2007, de 29 litros (INV, 2001,2007 ).

4 Tomamos este relevamiento como referente dado que no existen otros relevamientos que permitan observar en su conjunto la evolución de las bodegas y propiedades agrícolas en cuanto al origen de los capitales, al tipo de gestión, o al tipo de lugar que ocupan en la cadena productiva. Actualmente, la manera de hacer y comercializar los vinos ha modificado ampliamente el concepto de bodega y propiedad vitícola. 
han incorporado nuevas tecnologías agrícolas y vinícolas. Algunas de ellas, como FECOVITA ${ }^{5}$, han diversificado sus estrategias comerciales y hoy elaboran vinos finos tanto para el mercado interno como para el mercado externo ${ }^{6}$. El proceso de transformación es entonces muy heterogéneo y complejo. Más allá de los lineamientos generales, cada emprendimiento vitivinícola parece seguir su propia trayectoria dentro de ese amplio proceso de recomposición del sector vitivinícola.

\section{La reorganización del trabajo vitivinícola}

Si bien la recomposición del sector conlleva necesariamente una transformación de los modos de organización del trabajo, dentro de este heterogéneo universo no se ha conformado todavía un modelo generalizado y uniforme de gestión de la mano de obra, aunque se observan algunas tendencias. Las innovaciones en cuanto a la organización del trabajo aparecen principalmente en aquellos emprendimientos que participan directa o indirectamente del proceso de reconversión de la vitivinicultura. Este subsector está dominado por capitales extranjeros (Collado; Rofman, 2005) que han contribuido tanto a la concentración de la producción, como a la diversificación de los modos de participación en el sector vitivinícola. Actualmente, el $40 \%$ de los vinos finos es elaborado por cinco bodegas, entre las que se encuentran Chandon, Esmeralda, La Rural, López y Trapiche (Collado, 2001). A esta concentración se contrapone una enorme diversidad de estructuras productivas de diferentes tamaños. El Instituto $\mathrm{Na}-$ cional de Vitivinicultura registra cerca de 900 bodegas en la provincia de Mendoza, muchas de las cuales son emprendimientos comerciales realizados con capitales extranjeros.

En lo que respecta al sector primario, la recomposición de la vitivinicultura se manifiesta como una tendencia hacia una mayor integración vertical. Por una parte las grandes bodegas aumentan su capacidad de producir materia prima con la compra e implantación de nuevas hectáreas. Por otra parte, los pequeños productores, sobre todo aquellos que producen uvas finas se transforman en proveedores "estables"7 de los grandes establecimientos. Este modo de integración supone que los productores introduzcan nuevas tecnologías agrícolas y acepten el control de los ingenieros agrónomos y enólogos de las bodegas clientes durante el proceso productivo.

La incorporación de tecnologías como el riego por goteo automatizado, la malla antigranizo y el uso del sistema de conducción denominado "espaldero alto" conlleva la reorganización de las tareas agrícolas, y por consiguiente, implica una redefinición de la mano de obra demandada. Los nuevos sistemas de cultivo necesitan menos trabajadores, pero más especializados. Incluso el espaldero alto permite la automatización de ciertas labores. Cuando se compara la mano de obra requerida para trabajar los parrales (sistema clásico del modelo de producción de vino común) con la mano de obra requerida para el cultivo en espalderos altos (sistema de conducción de variedades finas), se observa que este último sistema necesita alrededor de un $11 \%$ menos de horas/ hombre por hectárea, pero un 12,5\% más de horas trabajadas por obreros calificados (Perlbach; Calderón; Rios Rolla, 2005).

También se observa un aumento de los trabajadores temporarios, contratados directamente o a través de agencias de empleo eventual (Fabio, 2010). La cosecha explica la mayor participación de trabajadores temporarios en el proceso de producción vitícola tanto en aquellos establecimientos que producen uvas para vinos de calidad como en aquellos que elaboran uvas comunes. El 90\% de los primeros y el 93\% de los segundos contratan cosechadores externos (Quantara; Goldfard, 2005). Datos publicados en los anuarios de la Dirección General de Estadísticas de Mendoza, muestran que durante el primer cuarto del siglo XX, en la cosecha el número de trabajadores se triplicaba (Salvatore, 1986, p. 244). Actualmente, la situación parece ser la misma. Los trabajadores permanentes representan apenas el 23\% del total de trabajadores vitícolas, y los temporarios el 77\% (Coviar, 2005). Sin embargo hoy, los trabajadores temporarios son

5 FeCoVitA (Federación de Cooperativas Vitivinícolas Argentinas), es una cooperativa de segundo grado que asocia a 31 cooperativas, integradas por más de 5000 productores y elaboradores vitivinícolas. Esta Federación de Cooperativas se hace cargo de la producción y fraccionamiento de vinos luego de la privatización de Bodegas Giol en 1989. Ver Fabre, 2005.

6 Entrevista realizada a uno de los gerentes de FECOVITA, en octubre 2009.

7 No existe entre los productores y los bodegueros ningún contrato escrito donde los últimos se comprometan a comprar la producción de los primeros a precios pre-establecidos. Quince o diez días antes de la cosecha, los bodegueros establecen la cantidad de uva que van a comprar y los precios. Si bien en la mayoría de los casos, las bodegas invierten en tecnología agrícola en esas propiedades, el riesgo empresarial (riesgo asociado a las incidencias climáticas en el caso de la agricultura) es asumido exclusivamente por el productor (Entrevista realizada a un productor de uvas finas del Valle de Uco, proveedor de Chandon, agosto 2009). 
también solicitados para realizar tareas permanentes, no sólo aquellas estacionales donde se necesita una mayor concentración de la mano de obra ${ }^{8}$.

En ese contexto de transformación, la necesidad de incorporar a la organización del trabajo un gran número de trabajadores temporarios, por una parte, y la búsqueda de reducir los costos laborales y las responsabilidades patronales, llevan a los empresarios a explorar distintos modos de contratación. Aparecen entonces dos formas alternativas de contratación que se desarrollan en los márgenes de la legalidad. Lo interesante es que esas alternativas no surgen directamente de los empresarios, sino que son los trabajadores, quienes frente a la pérdida de sus contratos como contratistas o como obreros rurales no calificados, generan formas colectivas de inserción en un mercado de trabajo excluyente.

Uno de estos mecanismos - la utilización colectiva de facturas de un trabajador autónomo - aparece durante un período muy corto, particularmente entre 1997 y 1999. La utilización colectiva de facturas no es más que una estrategia que responde a una coyuntura de desestructuración radical del mercado de trabajo vitícola.

La otra estrategia colectiva - la conformación de cooperativas de trabajo - se desarrolla incluso antes de que se inicie la reconversión del sector en los años 90, sin embargo su presencia en el mercado de trabajo vitícola es mayor a principios del siglo XXI.

\section{Colectivos invisibles}

Sobre todo al comienzo del proceso de reconversión de la producción vitivinícola de Mendoza, se observa la utilización de una estrategia muy particular de gestión de la mano de obra que pasa por un uso extensivo de la categoría "trabajador autónomo", es decir trabajador independiente.

La categoría "trabajador autónomo" fue creada en 1955 con el objeto de permitir que los trabajadores independientes, sólidamente integrados al mercado de trabajo, tuvieran acceso al sistema de jubilaciones y pensiones. Dado que el trabajador autónomo debe pagar sus impuestos y cotizaciones sociales, la inscripción en esta categoría estaba condicionada a un nivel mínimo de ingresos. En 1998, cuando se crea el régimen de monotributo, el nivel de ingresos exigido disminuye. Este régimen busca lograr el registro, tanto fiscal como en el sistema de seguridad social, de la mayoría de los trabajadores que realizan actividades informales. Este sistema prevé una categorización especial para los trabajadores rurales, es por ello que a fines de los 90 numerosos son los ex contratistas que se inscriben como monotributistas rurales y facturan sus servicios en tanto que trabajadores independientes.

La categoría "trabajador autónomo" va a jugar un rol central en la reconfiguración de la organización de las relaciones laborales en las regiones vitivinícolas argentinas, contribuyendo a la instauración de un modelo hiperflexible de gestión del trabajo. La contratación de los ex contratistas como trabajadores autónomos funciona como una especie de subcontratación o exteriorización del empleo (Lyon-Caen, 1995). Sin embargo, se trata de un modo de gestión de la mano de obra que no se estructura exactamente como la subcontratación, dado que resulta de la utilización irregular de la categoría "trabajador autónomo". En efecto, esta forma de externalización (o más bien falsa externalización) se acompaña de una negación de la relación de subordinación real que caracteriza la situación del trabajador rural inscripto como trabajador autónomo (Poblete, 2008a).

Concretamente, durante el proceso de reconversión de la industria vitivinícola, la externalización de la mano de obra responde a diferentes objetivos: 1) facilitar la adaptación del personal a las demandas técnicas del nuevo modo de producción; 2) reducir los costos laborales; 3 ) ajustar el volumen de trabajadores a los diferentes ciclos de la producción; 4) romper con la relación de proximidad que unía al empleador con el trabajador característica del modelo del contratista.

En primer lugar, la subcontratación aparece en las regiones vitivinícolas de Mendoza como un modo de adaptar rápidamente el modelo de organización del trabajo centrado en la figura del contratista a las exigencias impuestas por las nuevas tecnologías introducidas durante los años 1990. Los cambios tecnológi$\cos$, que tienen como objetivo permitir la producción de vinos de mayor calidad, implican una redefinición de las tareas agrícolas, y por consiguiente, demandan la participación de trabajadores con nuevos perfiles profesionales.

En segundo lugar, la subcontratación de trabajadores autónomos se presenta como una manera de reducir los costos laborales fijos. Durante la vigencia de la ley de Convertibilidad (1991-2002) que estableció la paridad entre el peso argentino y el dólar, toda industria que buscara insertarse en el mercado internacional necesitaba, para ser competitiva, reducir la parte del trabajo en el costo total del producto. La exigencia de bajar el precio del trabajo podía traducirse en ese momento en dos estrategias: la disminución del volumen del personal permanente y la reducción 
de las cargas patronales. La utilización de la categoría "trabajador autónomo" parece sintetizar ambas estrategias. Al subcontratar trabajadores autónomos, el empleador está eximido del pago de cargas patronales. Esta categoría se usa tanto para reemplazar a los trabajadores permanentes como para substituir a los trabajadores temporarios".

Quizá sea necesario subrayar que la disminución del costo del trabajo no se realiza vía el trabajo no registrado porque los empresarios no pueden recurrir a este tipo de trabajo de manera sistemática. Aún en los mercados de trabajo poco controlados por la inspección del trabajo, como lo son los mercados rurales, los empleadores no pueden justificar sus actividades sin declarar un cierto número de trabajadores al fisco.

En tercer lugar, la contratación de personal utilizando la categoría "trabajador autónomo" permite que se ajuste el volumen de trabajadores a las necesidades del ciclo cultural. Este modo de subcontratación otorga mayor flexibilidad que el uso de contratos de trabajo temporario, o incluso de trabajo eventual tal como aparecen estipulados en el Código del Trabajo dado que estos estatutos implican ciertas responsabilidades patronales, además del pago de cargas sociales.

Sin embargo, la adopción de la categoría "trabajador autónomo" como una de las principales categorías de contratación no responde exclusivamente a criterios económicos, sino que se relaciona también con la voluntad de romper la relación de dependencia entre el patrón y el contratista (Poblete, 2008c). Es por ello, que las empresas que se instalan a partir de los años 90 en Mendoza no renuevan el contrato de los contratistas, sino que les proponen ser recontratados en calidad de trabajadores autónomos. Los ex contratistas se ven obligados a registrarse ante el fisco y la seguridad social como prestadores de servicios, es decir, como empresas unipersonales. Sin embargo, su condición de trabajadores autónomos es sólo ficticia ya que los ex contratistas dependen económicamente de sus empleadores. Su integración en tanto que trabajadores autónomos no es más que una ficción legal que permite romper la relación tradicional entre el patrón y el contratista que caracterizaba al modelo del contratista.

Durante el período de transición en el cual el antiguo modelo de organización del trabajo es desmantelado y el nuevo modelo comienza lentamente a definir sus características fundamentales, se observa una forma extrema de externalización a través de la categoría "trabajador autónomo": el uso colectivo de facturas de trabajadores autónomos.

Se trata de una forma bastante particular de fraude en materia de derecho del trabajo, dado que el empleador no participa de manera directa del mismo. Ningún acuerdo, ni explícito ni implícito, se establece entre el empleador y el trabajador para que esta relación laboral fraudulenta pueda tener lugar. Los trabajadores presentan a sus empleadores, facturas para que el trabajo realizado pueda ser pagado; éstos últimos las reciben como si no estuvieran al tanto del tráfico de las mismas. En realidad, los trabajadores no buscan tampoco cometer un fraude laboral. En cierta medida, el fraude se les impone como único modo de participación en el mercado de trabajo. Estamos acá en presencia de lo que un legislador caracterizó como "una situación de fraude forzoso"10.

Debido a la baja remuneración y la irregularidad con la que reciben su paga cuando trabajan como jornaleros, la mayoría de los excontratistas no estaba en condiciones de pagar las elevadas cotizaciones sociales exigidas a los trabajadores autónomos. Sólo algunos, por ejemplo, aquellos empleados en las bodegas que perciben ingresos regulares, se registran como trabajadores autónomos. Entre quienes realizan actividades exclusivamente agrícolas, apenas un trabajador de cada diez está registrado como trabajador autónomo. Los otros, quienes no se inscriben porque saben que no podrán pagar ni los impuestos, ni la seguridad social como autónomos, están obligados a presentar facturas de otros trabajadores.

Marisa y Raúl nos confían:

Marisa - y no, mirá, como ser cuando lo echaron a él, nosotros tuvimos la desgracia que lo echaron, y lo tuvieron que operar. Y de ahí agarramos, después que él se sanó ya de la operación, le pedimos ahí el facturero, a un amigo mío y en una finca de enfrente, para ahí para aquel lado, y conseguimos trabajo. Como ser para la envoltura, y así.

Entrevistadora - ¿y cómo es lo del facturero?

Marisa - y no te lo dan, vos lo tenés que conseguir. Una que no te dan trabajo al día porque para ahí, en lo de Llorente, no te dan más. Vaya para allá. Y si no tenés casa no te dan trabajo. Porque ahí la finca no quiere darle trabajo a la gente que no tiene casa, porque no tiene casa para darle. Y acá que hay casa, no hay trabajo. Y si no, tenés que conseguirte facturero para trabajar al tanto. Temporario, así al tanto, viste. Y agarrás unos trabajitos y bueno, trabajás. Con el facturero tenés que pagar el monotributo que son 60 pesos, aparte...

Raúl - son 70, así tengas trabajo o no tengas...

Marisa - y son 70 pesos de monotributo, aparte tenés que, de cada factura que vos pagás, son el 3\% de la factura. Cuando llegás a fin de mes y la factura te da, 
porque es una por semana que tenés que entregar, que el 3\% de cada factura, más los 70 pesos, ¿cuánto te queda? Nada. Así que nosotros, hemos recurrido ahí a mi primo...

A raíz del costo que tienen las facturas, cada factura es utilizada para registrar el trabajo de varios trabajadores. Es por ello, que a pesar de que sólo una minoría de trabajadores está inscripta como trabajador autónomo, la mayoría puede facturar su trabajo como autónomo. Esto significa que cada trabajador inscripto le da al empleador facturas que acumulan el trabajo de un grupo de trabajadores bajo la forma de una prestación de servicios personales. En contrapartida, los trabajadores no registrados pagan al trabajador legalmente inscripto un porcentaje correspondiente a las cotizaciones del sistema de seguridad social y a los impuestos. Los trabajadores así reagrupados funcionan como "falsas" cooperativas de trabajo, como colectivos invisibles de trabajadores autónomos (Poblete, 2004).

La consecuencia directa de este modo de participación en el mercado de trabajo es la exclusión total del sistema de seguridad social. Prácticamente nueve de cada diez trabajadores quedan fuera del sistema. Sin embargo, la pérdida de protecciones sociales no parece inquietar a los falsos trabajadores autónomos, dado que de todas maneras aún como contratistas tenían un acceso muy limitado a ciertas protecciones sociales (Poblete, 2008b). Por el contrario, lo que parece más crítico para ellos, es la pérdida de los soportes sociales que les proveía el modelo del contratista, es decir la seguridad del empleo, el derecho a una casa y la seguridad de ingresos regulares (Poblete, 2008c).

Más allá de que la utilización de facturas prestadas aparece como otra variante del trabajo clandestino, en esta situación no es percibido como un problema por los trabajadores rurales. En efecto, el carácter formal o informal del trabajo parece completamente banal, dado que los excontratistas siempre estuvieron insertos en un mercado de trabajo que propone de manera indiscriminada tanto posiciones registradas como no registradas. Por consiguiente, el hecho de tener acceso a facturas prestadas no es percibido como ilegal, sino como una forma de adaptar los estatutos legales a las posibilidades del medio. Facturar colectivamente el trabajo de cada uno en una misma factura aparece como la única táctica (De Certeau, 1999) que permite a los trabajadores rurales recuperar un lugar incierto en un mercado de trabajo en plena recomposición.

Lamentablemente, muchas veces, los trabajadores no tienen la posibilidad de elegir otra forma contractual. Las empresas proponen sólo trabajo a trabajadores autónomos. Entonces, aquellos que no tienen la posibilidad de inscribirse como trabajadores autónomos tienen que pedir prestadas facturas a los trabajadores inscriptos. Sin embargo, el intercambio de facturas no es algo simple. Dado el costo de las cotizaciones, el intercambio de facturas aparece como una práctica basada en relaciones de confianza. De esta manera, las redes de sociabilidad primaria (Castel, 1995) se transforman en un refugio porque el procurarse facturas depende de la reactualización de los lazos más fuertes (Granovetter, 2000, p. 61), es decir de los lazos de parentesco y de vecindad.

\section{Falsos colectivos}

Las cooperativas de trabajo como modo asociativo de integración al mercado de trabajo fueron reguladas por primera vez por la ley 20.337 en 1973. Sin embargo, las mismas fueron frecuentemente utilizadas como empresas de servicios eventuales con el objeto de obtener las ventajas impositivas acordadas a este tipo de institución y evadir las cargas sociales de los trabajadores inscriptos como asociados. Es por ello que a partir de 1994, para evitar el uso de las cooperativas de trabajo como mecanismo de fraude laboral y fiscal se prohíbe el funcionamiento de aquellas "que para el cumplimiento de su objetivo social, prevean la contratación de los servicios cooperativos por terceras personas, utilizando la fuerza de trabajo de sus asociados" (Decreto PEN 2015/1994). Sin embargo, esta prohibición es cuestionada jurídicamente, y numerosos son los fallos judiciales que desconocen su validez, autorizando el funcionamiento de cooperativas de trabajo para brindar servicios a terceros.

Recién en 2004, en el marco de la Reforma del Código de Trabajo, se resuelve la ambigüedad jurídica de las cooperativas de trabajo. La ley 25.877 establece en su artículo 40 que "las cooperativas de trabajo no podrán actuar como empresas de provisión de servicios eventuales, ni de temporada, ni de cualquier otro modo brindar servicios propios de las agencias de colocación." Según la misma ley, la constatación de fraude laboral será penalizada con la obligación de reconocer a los asociados como "trabajadores dependientes de la empresa usuaria para la cual presten servicios, a los efectos de la aplicación de la legislación laboral y de la seguridad social."

A pesar de los intentos de regulación de las cooperativas de trabajo, las mismas no dejaron de multiplicarse aún después de 2004, sobre todo en mercados de trabajo poco controlados como lo es el mercado de trabajo agrícola. En el caso particular de ese mercado de trabajo, resulta difícil establecer la formalidad o informalidad de las posiciones ocupadas por los trabajadores. En la mayoría de los casos, se trata de posiciones mixtas, es decir, ni completamente formales, ni totalmente informales.

A partir de los años 1990, la presencia de las cooperativas de trabajo de trabajadores rurales aumenta 
visiblemente. Tanto las grandes empresas que buscan bajar los costos laborales fijos para ser más competitivas en el mercado externo, como las pequeñas empresas que intentan disminuir los costos y responsabilidades patronales, recurren a las cooperativas de trabajo para realizar tareas temporarias, así como también tareas permanentes. Esta modalidad de movilización del trabajo aparece como una alternativa para los trabajadores que habían sido despedidos en tanto que contratistas. En algunos casos son ellos mismo quienes toman la iniciativa de asociarse, en otros, son los dueños de las propiedades agrícolas quienes impulsan la conformación de cooperativas como modo de externalización de la mano de obra.

Jorge y Amalia nos contaban, en 1999:

Jorge -acá, cuando nos quitaron el contrato, con los otros dijimos que nos íbamos a hacer una cooperativa. Porque es fácil de hacer una cooperativa. Nos juntamos unos cuantos y vamos a la finca, allá, a decir que somos una cooperativa y que queremos trabajo... y te dan, te dan trabajo.

Amalia -te dan trabajo pero después se arman los líos...

Jorge -lo que pasa es que los patrones no quieren ocuparse de nada, viste. Le dan la plata al que presentó la cooperativa, como ser el jefe de la cooperativa, y después él se las tiene que arreglar con los otros. Y viste como es. Que yo quiero tanto, que el otro no vino, que no laburó, que yo tengo el nene enfermo, y así, no termina más la cosa. Te toca a vos controlar a los otros, pero no como contratista, más como capataz, como cuadrillero...

Amalia - ellos habían querido hacer la cooperativa, pero no sabían qué era así de complicado. Además, siempre están los que faltan y toca salir a buscar gente. Yo tenía que ir ahí por las casas preguntando por los muchachos cuando había alguno que se perdía. Y son así los muchachos, pa' trabajar...

Tal como nos cuentan Amalia y Jorge, el funcionamiento de las cooperativas de trabajo demanda un cierto nivel de organización interna, que en muchos casos fue imposible de lograr. La falta de mecanismos que permitieran regular la participación de los socios llevó a muchas de las cooperativas al fracaso. Sin embargo, fue distinto cuando fueron los nuevos dueños los que propusieron a los antiguos contratistas que formaran una cooperativa de trabajo. En esos casos, la organización del trabajo siguió siendo la misma y los pagos casi idénticos. Cada contratista siguió siendo responsable con su familia del cultivo de un predio determinado, recibiendo mensualmente un salario, así como una compensación especial luego de la cosecha. La única diferencia era que el propietario declaraba la subcontratación de servicios a través de la cooperativa de trabajo, lo que le permitía evadir el pago de cargas patronales.
Con el correr de los años, y frente a formas similares de organización del trabajo, las cooperativas empezaron a ser vistas como el modo de inserción laboral más precario, y entonces menos deseable. Las cooperativas dejaron de ser una alternativa válida para aquellos que perdieron un puesto estable en el mercado de trabajo, para transformarse en el modo de inserción laboral de los que no podían acceder a otro tipo de estatuto.

\section{Conclusiones}

Tradicionalmente, el trabajo agrícola en las regiones vitivinícolas de Mendoza estuvo organizado en torno a dos colectivos muy diferentes. Por un lado, la familia que regulaba en tanto que unidad doméstica, la incorporación de los trabajadores inactivos en los momentos de mayor demanda de mano de obra. Por otro lado, las "cuadrillas" conformadas por trabajadores temporarios, por lo general externos a la región, dirigidas por el "cuadrillero" que cumplía el rol de mediador entre el patrón y los obreros. Las cuadrillas fueron desde sus orígenes hasta la actualidad una manera de organizar el trabajo no registrado.

Esta tradición parece reflejarse también en los nuevos modos de gestión del trabajo que surgen o se intensifican luego de la reconversión productiva de la vitivinicultura mendocina. Tanto el uso colectivo de facturas de trabajadores autónomos como las falsas cooperativas de trabajo aparecen, durante los años 1990, como modos alternativos de integración en el mercado de trabajo. Los trabajadores expulsados del mercado de trabajo por no tener las competencias necesarias para realizar las nuevas tareas impuestas por el modelo vitivinícola de exportación, encuentran en estas dos formas colectivas de gestión del trabajo una alternativa a la exclusión del mercado de trabajo.

La conformación de estos colectivos no responde a la persecución de objetivos comunes, sino a la coincidencia de objetivos individuales, o mejor dicho, de la necesidad individual de incorporarse bajo cualquier estatuto al mercado de trabajo. Es por ello, que se trata de colectivos con muy poca consistencia. Incluso podríamos cuestionar su existencia como tales.

En el caso de los préstamos de facturas, según nuestros entrevistados, aquellos que facturaban utilizando facturas de un trabajador autónomo "eran siempre los mismos". Dado el costo de las facturas, es decir, de los impuestos y cotizaciones asociados al estatuto de trabajador autónomo, quien facturaba por otros necesitaba estar seguro de que éstos iban a rembolsarle la parte correspondiente a los impuestos y cotizaciones. Los préstamos quedaban entonces reducidos a grupos pequeños, que resultaban de la actualización de lazos fuertes (Granovetter, 2000). Si bien aquí no apare- 
ce el colectivo como una entidad, podemos decir que ese colectivo invisible se funda en otros colectivos ya existentes.

En el caso de las falsas cooperativas de trabajo, el colectivo no tiene ninguna consistencia. Se observa más bien la producción de una ficción de colectivo. Los trabajadores que desempeñan tareas como asociados a esas cooperativas no sienten ninguna adhesión particular a las mismas. Es más, pueden trabajar para

\section{Referências}

ASPIAZU, Daniel; BASUALDO, Eduardo. El complejo vitivinícola argentino en los noventa: potencialidades y restricciones. Cepal, 2001.

AZPIAZU, Daniel; BASUALDO, Eduardo. Estudios sectoriales. Componente: Industria vitivinícola. Cepal-ONU, 2003.

BOCCO, Adriana et al. Reconversión y empleo en la industria del vino. Estructura productiva y dinámica del empleo en el complejo vitivinícola: un análisis del sector bodeguero nacional. Buenos Aires: Ministerio de Trabajo, Empleo y Seguridad Social, 2005.

BRAVO-BOUYSSY, Ketty; BRIOLE, Alain. L'impact des pratiques d'externalisation sur les frontières de l'organisation et du salarial. Économies et Sociétés, Économie et gestion de services , n. 6, p. 1759-1779, 2004.

CASTEL, Robert. Les métamorphoses de la question sociale: une chronique du salariat. Paris: Gallimard, 1995.

COLlADO, Patricia. Mercado de trabajo en Mendoza: transformaciones y perspectives. In: V CONGRESO NACIONAL DE ESTUDIOS DEL TRABAJO (ASET). Buenos Aires, 2001. Actas..., 2001.

COLLADO, Patricia; ROFMAN, Alejandro. El impacto de la crisis de los años 2001-2002 sobre el circuito agroindustrial vitivinícola y los agentes económicos que lo integran. In: IV JORNADAS INTERDISCIPLINARIAS DE ESTUDIOS SOCIALES Y AGROINDUSTRIALES. Actas..., Buenos Aires: FCE-UBA, 2005.

COVIAR. Informe de la COVIAR. Mendoza, 2005. Disponível em: <http://www.vitivinicultura2020.com.ar/>. Acesso em: 2010.

DE CERTEAU, Michel. L'invention du quotidien. Paris: Éditions Gallimard, 1999.

FABIO, José Francisco. Regulación social de la transitoriedad. EL Mercado de trabajo en la producción de uvas en Mendoza, Argentina. Cuadernos de Desarrollo Rural, v. 7, n. 64, p. 33-57, 2010.

GAGO, Alberto; DE LA TORRE, Delia. Impactos territoriales de la reestructuración en la agroindustria de base vitícola en la región de Cuyo. San Juan: Facultad de Ciencias Sociales, Instituto de Investigaciones Económicas, Universidad $\mathrm{Na}$ cional de San Juan, 1996. distintas cooperativas a la vez, o de manera sucesiva. La participación en las cooperativas de trabajo es apenas una manera poder trabajar al día o "al tanto". Esta participación depende de la posibilidad de actualizar lazos débiles (Granovetter, 2000).

Aún si estas formas colectivas de movilización del trabajo se estructuran en base a colectivos inconsistentes, la manera en la que se organizan en un momento de fuerte desestructuración y reestructuración del mercado de trabajo, pone en evidencia que el acceso al mercado de trabajo vitícola necesita de la mediación de alguna forma del colectivo.

GRANOVETTER, Mark. Le marche autrement. Paris: Desclée de Brouwer, 2000.

HEREDIA, Mariana; POBLETE, Lorena. La estratificación socio-laboral en un caso de globalización exitosa: la vitivinicultura mendocina, 2010. (Inédito).

INV: Instituto Nacional de la Vitivinicultura. Anuarios: 1978-2008.

LYON-CAEN, Gérard. Où mènent les mauvais chemins. Droit Social, n.7/8, p. 647-654, 1995.

MACLAINE PONT, Pollo; THOMAS, Hernán. Como fue que el viñedo adquirió importancia? Significados de las vides, calidades de las uvas y cambio socio-técnico en la producción vinícola de Mendoza. Apuntes de Investigación, n. 15, p. 77-96, 2009.

MELLADO, Virginia. Empresariado y vitivinicultura: trayectoria y caída del grupo Greco. In: MATEU, Ana María; STEIN, Steve (Org.). El vino y sus revoluciones: una antología histórica sobre el desarrollo de la industria vitivinícola argentina. Mendoza: EDIUNC, 2008.

MORIN, Marie-Laure (Org.). Prestation de travail et activité de service. Paris: La Documentation Française, 1999.

NEIMAN, Guillermo; BOCCO, Adriana. Estrategias empresariales y transnacionalización de la vitivinicultura en la Argentina. In: BARBOSA CAVALCANTI, Josefa; NEIMAN, Guillermo (Eds.). Acerca de la globalización en la agricultura. Territorios, empresas y desarrollo local en América Latina. Buenos Aires: Ciccus, 2005.

PERLBACH, Iris; CALDERÓN, Mónica; RÍOS ROLLA, Mariela. La generación de empleo en la cadena vitivinícola. A través de la matriz de insumo producto. In: VII CONGRESO NACIONAL DE ESTUDIOS DEL TRABAJO (ASET), Buenos Aires, 2005. Actas..., 2005. POBLETE, Lorena. De la gestion de l'autonomie. Parcours de travailleurs autonomes argentins dans les années 90. Tesis (Doctorado en sociología) - Escuela de Altos Estudios en Sciencias Sociales. París, 2008a. Disponível em: <http://tel. archives-ouvertes.fr/tel-00407491/fr/>. Acesso em: 2010. POBLETE, Lorena. La burocratización de las políticas sociales. La administración de programas alimentarios en la Argentina rural. Perfiles Latinoamericanos, n. 31, p. 151-168, 2008b. 
POBLETE, Lorena. De la pauvreté stable à l'instabilité dans la pauvreté. Le cas des travailleurs autonomes des régions vitivinicoles de l'Argentine (1995-1999). Études Rurales, n. 181, p. 61-73, 2008c.

POBLETE, Lorena. Les collectifs invisibles: le cas de travailleurs ruraux "autonomes" (Mendoza, Argentine). In: I COLLOQUE DE L'ASSOCIATION FRANÇAISE DE SOCIOLOGIE, Paris, 2004. Actes..., 2004.

QUARANTA, Germán; GOLDFARB, Lucía. La mano de obra en las producciones de vid cuyanas. In: VII CONGRESO NACIONAL DE ESTUDIOS DEL TRABAJO
(ASET), Buenos Aires, 2005. Actes..., 2005.

SALVATORE, Ricardo. Control del trabajo y discriminación el sistema de contratistas en Mendoza, Argentina, 1880-1920. Desarrollo Económico, v. 26, n.102, p. 229-253, 1986.

SERVAIS, Jean-Michel. La externalización de la relación de trabajo en los países europeos, Revista Latinoamericana de Derecho Social, n.10, p.263-324, 2010.

\title{
The collective as a way to labour access: the case of viticultural workers in Mendoza, Argentina (1995-2010)
}

\begin{abstract}
The viticultural labor organization, which characterized the internal market production model in Argentina, has had the family as it axis. By the fact that different family members have participated in the agricultural work, this kind of organization could be adapted to the demands of the agricultural cycle.

Beginning in the 90s, when the wine production model became oriented to the external market, the new agricultural technologies were introduced and, as a result, the labor organization changed. In this context of labor market transformation, two associative forms occur and allow the insertion of those workers once expelled by the new model. The main goal of this paperwork is to analyse the manners in which these collectives were formed and how they work. The study cases are: the collective usage of the category "self-employment" and the informal labor cooperatives.
\end{abstract}

Keywords: collective; agricultural work; industrial reconvertion; precarious work; Argentina.

\section{O coletivo como caminho de acesso ao trabalho. $O$ caso dos trabalhadores vitícolas de Mendoza, Argentina (1995-2010)}

\section{Resumo}

A organização do trabalho vitícola que caracterizou o modelo de produção centrado no mercado interno tinha como eixo à família. Pelo fato de diferentes membros da família participarem do trabalho agrícola, esse tipo de organização podia se adaptar às demandas do ciclo do cultivo. A partir dos anos 90, quando o modelo de produção vitivinícola muda a orientação para o mercado externo, novas tecnologias agrícolas são introduzidas e, portanto, muda o modo pelo qual o trabalho é organizado.

Nesse contexto de transformação do mercado de trabalho aparecem duas formas associativas que permitem a inserção laboral dos trabalhadores expulsos pelo novo modelo. O objetivo deste artigo é analisar a maneira pela qual são constituídos e como funcionam esses coletivos. Os casos estudados são: o uso coletivo da categoria "trabalhador autônomo" e as cooperativas de trabalho informais.

Palavras-chave: coletivo; trabalho agrícola; reconversão industrial; precariedade no trabalho; Argentina.

Data de recebimento do artigo: 30-11-2010

Data de aprovação do artigo: 13-03-2011 